\title{
PERIODONTOLOGY, WITH SPECIAL REFERENCE TO RECESSION OF THE GUMS ${ }^{1}$
}

\author{
ANDREW J. McDONAGH \\ Toronto, Ontario, Canada
}

CONTENTS

Definition of recession: kinds and causes........................ 423

Recession may be stopped and the condition rectified.................. 429

Recession does not occur on teeth that are properly crowned...........430

Illustration of success in efforts to bring back the gum line after its recession. 432

Methods for the treatment of recession. . . . . . . . . . . . . . . . . . . . . . . 436

The author's procedure................................... 436

The Adams silver nitrate and iodin method. . . . . . . . . . . . . . 438

The title of my paper, "periodontology," is a comprehensive title, if comparatively new. I do not intend to exhaust all the different phases of periodontology; my effort will be to make my paper as practical as possible, and particularly to take up one phase of the subject which is not very often written about but which, nevertheless, is a very serious problem to a great number in our profession. I have been looking through the dental literature for articles entitled "receding gums" or for articles paying particular attention to that phase of periodontoclasia, and have been surprised to find that so few writers have given us anything about the subject, though it is so important and enters into the work of every day.

\section{DEFINITION OF RECESSION: KINDS AND CAUSES}

In a former article $I$ made the statement that the term "receding gums" is a misnomer; in other words, that such a thing does not exist in the human mouth. That statement is true if we accept the concep-

1 Read before the First District Dental Society of the State of New York, at a meeting in New York City, October 6, 1919. See page cvii, of the section on Proceedings of Dental and Stomatological Societies, for a report of the discussion of this paper at that meeting by Drs. Arthur H. Merritt, Paul R. Stillman, M. L. Rhein and Anna G. Freedman, of New York City; and Dr. McDonagh. 
tion ordinarily taken of receding gums. There is however a condition evolved in the mouth, possibly normally and, according to Hopewell-Smith, universally in every adult, which actually does produce recession of the gums. Hopewell-Smith tells us that no sooner is the alveolus built up to its fullest extent than it starts to break down. There is a paragraph in Dental Cosmos (1911) on this point, in which Hopewell-Smith speaks as follows of a patient in middle age:

"In the mouths of people in middle age, a startling fact may be frequently observed. Without any signs of gingivitis whatever, or of the presence of tartar or pyorrhoea, when the gum tissues are what one would call normal and healthy, and the adjacent teeth are fully functional and free from caries, decalcification or halisteresis of the free edge of the osseous socket may be beginning. It must be remembered that the bone forming the dental sockets is peripheral and (as was pointed out by the writer nine years ago in the Dental Cosmos, 1902, p. 549) is structurally different from compact bone properly formed elsewhere. This ill constructed attachment and foundation of the teeth easily and early falls a prey to disturbances in the vascular system of the jaws, and soon begins to degenerate and atrophy, after an acute attack of anaemia, or after long continued fever, rheumatism, etc."

In a paper read before the Odontological Society of Toronto, Hopewell-Smith goes further, stating that this dissolving of the crest of the alveolus, which he speaks of, commences about the age of twenty-five. We know that the alveolus is the supporting structure of the gums. Consequently, if the calcareous foundation disappears, the gums will follow to a certain extent, and we will have a natural, and if Hopewell-Smith is right, a normal recession of the gums because it is universal. I have wondered however, since I began to study this question, whether, if Hopewell-Smith's subjects had been treated by a periodontist from the time they were eighteen years old until they were thirty, he would have had the results which he has described and shown. I must say, I doubt it. I doubt it on account of the obvious influence of oral prophylaxis and because of the conditions shown in the illustrations I shall throw on the screen this evening.

Recession of the gum line may be the result of many and varied causes. Sometimes the dentist, deliberately or unintentionally by his operations or instructions, may be the cause. Sometimes the cause is 
in the actions of the patient himself. More often, $I$ believe, the cause is more obscure and more intimately connected with the blood circulation of the part, or with the general blood circulation, than is generally supposed.

As regards the dentist: sometimes we are guilty in the manner of our operation, causing recession of the gum line, which perhaps is not necessary, inasmuch as we could rectify the condition without causing the great recession that we do. Have in mind the picture of the surgical procedure which was performed or demonstrated by Riggs some years ago, and which today is followed with slight variation by a number of operators, and sometimes most certainly is followed to excess. The style of operation referred to is one which operators use to remove all of the diseased gum tissue and all of the gum tissue that covers disease; in other words, to cut away all of the tissue which can possibly form a pocket and, depending on nature to grow new tissue to cover the denuded part, in that way to "cure" the disease. Certainly that does "cure" the disease, just as cutting off a diseased finger makes a cure; and there is no doubt in my mind that at times it is a good thing to do. I practise it occasionally but not very often. It is radical and in the majority of cases unnecessary; but when it is necessary, when a more simple operation will not avail-in other words, in extreme cases, when you could not get healing otherwise-I consider it a good operation to perform. But, you know, the man who is successful with only one kind of operation thinks that that operation is the only one which is ever successful. The man, however, who has tried other methods of operation, and who has succeeded, tells you that to follow only one line of operation is nothing short of folly.

I must say I cannot agree with the extremists. In the majority of cases, it is not necessary, nor is it wise, to cut away the gum tissue and the projecting alveolar tissue in order to get a cure for suppurative periodontoclasia. In a great many cases when the tissue is cut away, we see objectionable recession of the gum. I have seen mouths, upon which this operation was performed, with the roots of the teeth very much exposed. On the other hand I have seen cases, where this operation had been performed, which looked very well and the patient was comfortable. 
In this paper, I do not intend to go very seriously into the question whether the gum will attach again to the tooth structure or not, or whether it will simply adjust itself to the position of the tissues and simulate a cure. That question has been debated very often and very strenuously.

There is another method of operating which has quite a disfiguring effect-a method which I must say I practised quite extensively at one time-that of cutting a slit in the gum to the bottom of the pocket and operating on the tissues after having cut that slit. After operating, the flap is brought back into place as well as possible, suturing if necessary to keep it in place, and in that way getting as good healing as possible. But the objection to that method is the great recession of the gum line that almost invariably occurs afterwards.

There is also recession of the gums in old age, which is considered almost inevitable.

We also have the recession that sometimes results from faulty restorative operations, but which I believe is not very common; and, unfortunately, recession is also a result of orthodontia. You may tell me it is the result of faulty orthodontia and I will say I cannot contradict you, but I do not believe it is always the fact. I have seen cases where recession took place after orthodontia, and where it did not seem to be the fault of the orthodontist or the fault of the dentist who did the orthodontic work. However that may be, we have those cases and we must deal with them when they present themselves.

What can be done to relieve or rectify this condition? In the first place we must try to get at the cause; and, if we understand the cause, perhaps we can more easily decide what should be done for the case. Recession of the gums takes place when? In the child or in the adult? In the great majority of cases it occurs in the adult, coincident with other forms of periodontoclasia. True, we do sometimes find it in children; but cases of this sort are rare.

Recession of the gums, as I take the expression, means literally that the gums recede from their ordinary or normal position, that they do not disappear or dissolve away, but that the underlying tissues give way and the gums recede. Or, if you wish, the gingiva recedes, making a distinction between the gingiva and the gum tissue. In order that the gingiva may recede, of course the alveolar process must 
disappear or recede, and the gum tissue must also disappear or recede; and here is where Hopewell-Smith's investigations serve us. He says that at or after maturity the crest of the alveolar bone disappears and in that manner allows the gum to recede. That being true, there is a physiological recession of the gum, provided that the disappearance of the crest of the bone is physiological. But ordinarily what we call recession of the gum is not recession of the gum; it is disappearance, death, or atrophy, beginning at the gingival margin. In the majority of people, the bony support of the gum tissue, the alveolus, disappears either as a result of the atrophy or concurrently with it, resulting in exposure of the neck of the tooth sometimes to a very great distance. If the process is not checked, the tooth may be stripped to the apex of the root.

Although this condition is so common and although it is looked upon as being almost inevitable, my experience has convinced me that any periodontist or any dentist who has suitable instruments, and is willing to give it the time and attention necessary, can absolutely stop so-called recession of the gums in practically every case, and can do a great deal to lessen if not to stop the amount of true recession of the gums.

Let us consider where this recession usually takes place first. Is it not over the upper cuspid teeth and central teeth, and sometimes over the buccal roots of the molar teeth, where there is a faulty development of investing tissues. In the lower jaw as in the upper jaw, the anatomy plays an important part; if the labial investing tissues are thin, recession is liable to take place over all the incisors and cuspids. Observe the point of similarity in both the lower and upper jaws. The gum disappears from the gingival portion of the roots of the teeth on the lateral side if the investing tissues are not full and supported with a good blood circulation. Take for example the prominent root of the upper cuspid and note that the upper lateral which is not prominent, is, we may say, never the first to be attacked.

What is the cause of the disappearance of the gum over the prominent places in the mouth? We are told by a great many authorities that it is the manner of brushing the teeth and the kind of brush used. That is true in some cases no doubt. Faulty brushing is a great factor, and poorly made brushes are responsible for a certain amount of 
cutting away of the thin edge of the gum at the gingival margin and cutting ridges in the structure of the tooth. Then there is formed not only a sharp edge in the tissue of the tooth, just at the gum margin, but also in the place most favorable for the development of recession of the gums. I must say I cannot agree that this is the greatest factor in the disappearance of the gum tissue over these prominent teeth. It seems to me it is usually the result of atrophy, not caused by mechanical means, not caused by brushing or by massage as is sometimes said, but caused by the meagerness of the nutrition supplied to the tissue, resulting in molecular death of the tissue at the gingival margin. In the positions over the cuspid and central teeth, for instance the flow of blood is not so free as it is in other parts of the mouth. The gum is stretched in that particular position and, being stretched, the flow of blood is not so free and not so great as in other parts of the mouth.

In this connection, let us consider that there may be a vitiation of the blood stream. Talbot tells us-and he seems to know the truth of his statement-that, if the blood stream becomes vitiated or thickened, the interference with the flow to the small arteries must necessarily be great. This theory of Talbot's has been borne out and corroborated quite conclusively by the results of experiments by Price, which have been shown in moving pictures. In these pictures, Price shows contamination of the blood stream by the invasion of microorganisms and their by-products, a great object lesson along this line. Outside of this fact, however, that the blood finds difficulty in flowing through small arterioles under certain conditions of the blood and of the blood vessels, particularly the small blood vessels, there are local causes and factors which have to be taken into consideration.

I spoke of the fact that the gum is thin in certain positions and is not well supplied with blood, because of the prominence of the underlying bone and tooth structure. We must remember also that the bone becomes less richly supplied with blood vessels as we grow older. Therefore we would expect to find recession of the gums as years advance, which we all know is a fact. Contemporaneously, we find that, just under the gingival margin in every adult, there are microörganisms and also as a rule a small quantity of calcareous deposit. These microörganisms produce an irritating material which has a congesting effect on the gum tissue. The mechanical irritation of the accom- 
panying calcareous deposits has a similar influence. Combining the irritations by the microörganisms and calcareous deposits with the paucity of the blood supply, we have an ideal condition for the death of the tissue. The tissue which is furthest from the center of circulation will be the first to die, unless by accident there is some peculiar construction of the bone which can cut off the blood supply and allow a large quantity of tissue to atrophy, as sometimes is the case. This however is not of very frequent occurrence, so that ordinarily there is molecular death of the tissue, beginning at the extreme gingival margin and extending as far as is necessary for the death of the tissues, till we reach a position where the blood supply is richer and necessarily the soft tissues are thicker.

I grant that mechanical irritants such as salivary calculus do not always cause recession but that they sometimes cause congestion and hypertrophy of the tissue. Particularly is this true when the irritation is not of long duration. But this unhealthy condition of the soft tissues, which is the result of mechanical irritation, will usually resolve itself into a deterioration and breaking down of all parts involved; and, unlike a molecular death and slow disappearance of the gum, congestion and hypertrophy lead to constitutional complications. One may dispute, and dispute sincerely, the assertion that the blood circulation in the young can be so constricted in the mouth where anastomosis is so free, that there may be atrophy of the soft tissues, but under certain exceptional conditions atrophy occurs in the young as well as in persons of more advanced years. We would never think of disputing the fact that tissues that are not well supplied with blood, die and are sloughed from the remaining tissue, be it in the mouth or in any other part of the body, but that we can prevent this atrophy in the mouth and restore the normal conditions by skillful manipulations, no doubt requires proof and ocular demonstration.

RECESSION MAY BE STOPPED AND THE CONDITION RECTIFIED

Models can be shown-many of them-obtained before and after treatment, proving that, if you treat the teeth at the gingival margin and treat the tissues concerned as well as the teeth, and do your work properly, you can absolutely stop the so-called recession of the gums 
and, without a great deal of trouble, bring back, to a small extent at least, the gingiva towards its normal line. That is the point that I particularly want to make in this paper. I want to emphasize the fact that in every case I have seen, it was a comparatively easy matter to stop the so-called recession of the gums. In order to prove that point to you and bring it before your minds vividly, I am going to show you a few slides (figs. 1-11). I have the models here on exhibition from which the slides were made.

\section{Recession does not occur on teeth that are properly crowned}

You know there was a theory or rather a doctrine, upheld by many teachers in dentistry, that dead teeth were never affected by periodontoclasia or, as they used to say, by "pyorrhoea." Latter day teaching has a tendency the other way; and we, who are making a specialty of treating the periodontal tissues, find it very difficult if not impossible to get the tissues to hold properly when there is a pocket around an old devitalized tooth. But there was reason in the old doctrine, there was some truth in it, although it was not all truth.

I am going to show you some slides that demonstrate the fact that if a crown is properly put on a tooth-I say properly from a periodontist's standpoint-recession of the gum will not occur; and, if you get the occlusion right, you are not apt to have a loosening of that tooth (figs. 1-5). We must not forget that occlusion is a very important factor in artificial substitutes for the natural teeth, more so perhaps than with natural teeth, and without doubt more apt to be faulty.

The first slide I will now show you (fig. 1) illustrates conditions in a patient thirty years old. The upper left lateral was crowned at the age of twenty-three with a half-band crown; consequently it has been in place seven years. The gums on all the other teeth have receded. You can see that it is not a matter of natural teeth abrading more easily than porcelain teeth, because there are no lines of abrasion on the natural teeth.

The second slide (fig. 2) pertains to a patient, forty-eight years old. A crown has been on the upper right lateral for about fifteen years, so that when it was set the patient was a little over thirty, and in all 
probability the gums had receded a little at that time, as the position of the crown shows. Since the crown was placed in position, recession has stopped on that tooth but has continued on all the other teeth. In this case you see abrasion.

The third slide (fig. 3) shows conditions in a patient about thirtyeight years old. This crown differs from the other crowns in being an all-gold telescope crown. It was put on when the patient was twentyfour years old, therefore was on for fourteen years. As you will see, the gums have receded on all the teeth in the mouth except on that one. This tooth appeared to be vital.

The fourth slide (fig. 4) demonstrates similar effects in a patient thirty-five years old. There is an upper right lateral with a bandless crown in place for twelve years; put on when the patient was twentythree years old. The gums have receded on all the other teeth in the mouth excepting that one. There is no abrasion on any tooth.

The fifth slide (fig. 5) shows the teeth of the youngest patient on the list: twenty years old. The right upper central has a banded crown. Recession has taken place on all the other teeth in the mouth, upper and lower.

In this collection (figs. 1-5) we have a full-band crown, a half-band crown, a telescope crown which of course is a full-band crown, and one with no band at all. There is one common practice in making such crowns or rather in preparing the roots for the crowns, namely, in every case the periphery of the root is reduced in size. In reducing that periphery the dentist does two things; he removes all foreign material, dead tissue and deposit, and helps the gingival circulation, notwithstanding the fact that he must cause the formation of some cicatricial tissue incidentally and make a good fit for the crown. The result of removing the dead tissue and deposit is that he gets a surgically clean wound, which will be protected by fibrous or cicatricial tissue, and he makes it impossible for the gum to become stretched over that particular root, so long as the other roots hold in position. Notwithstanding the fact that a small amount of contraction takes place in the cicatrix, in my experience this contraction is much less serious in the mouth than in other parts of the body.

The foregoing might lead one to assume that it is advisable and good practice to devitalize teeth and put on crowns; whereas the very 
opposite is true. Thousands and thousands of teeth and numerous lives have been lost, and many people have been made cripples, by the devitalization of teeth. In this connection radiographic and other examinations show that it does not make any difference whether the teeth which are crowned are septic or non-septic, so far as the recession of the gum line is concerned.

Some of the teeth I have shown you, on which the gums were in perfect condition at the gingival margin, when radiographed several years after being crowned, had large septic masses at their apices. This is all that it is necessary to say regarding that point.

The fact that the gum does not recede on teeth when crowned in this particular way and with this particular kind of skill, must teach us that there is a method of preventing recession of the gums; and possibly of restoring to normal conditions; gums which have already started to recede.

Some years ago, Harlan advocated cutting the gum tissue away from the tooth and away from the bone without splitting the gum at the gingival line; then, by a semi-lunar incision, separating a gingival portion from the rest of the gum, bringing that portion down bodily on the tooth, and filling in the wound with sulphite of copper till it oozed out at the gingival margin; and repeating this operation often enough, till the gum is brought back to its normal position. I have tried that a number of times and find it can be done, but it needs exceedingly careful handling and, when you get through, you have a very deep gingival crevice. The gum is loosened and there is a free flow of blood through it, if you have been successful. If you have not been successful in your operation, the root is denuded twice as far as it was before.

Illustration of success in efforts to bring back the gum line after its recession

The next few slides are intended to show what can be done to bring back the gum to the normal line in extreme cases (figs.6-11). The young lady who allowed me to get the first four of these slides has also been good enough to exhibit herself at several dental meetings. These slides show that the gum, which was stripped to the apex of the tooth, has been forced to grow back until it entirely covered the 

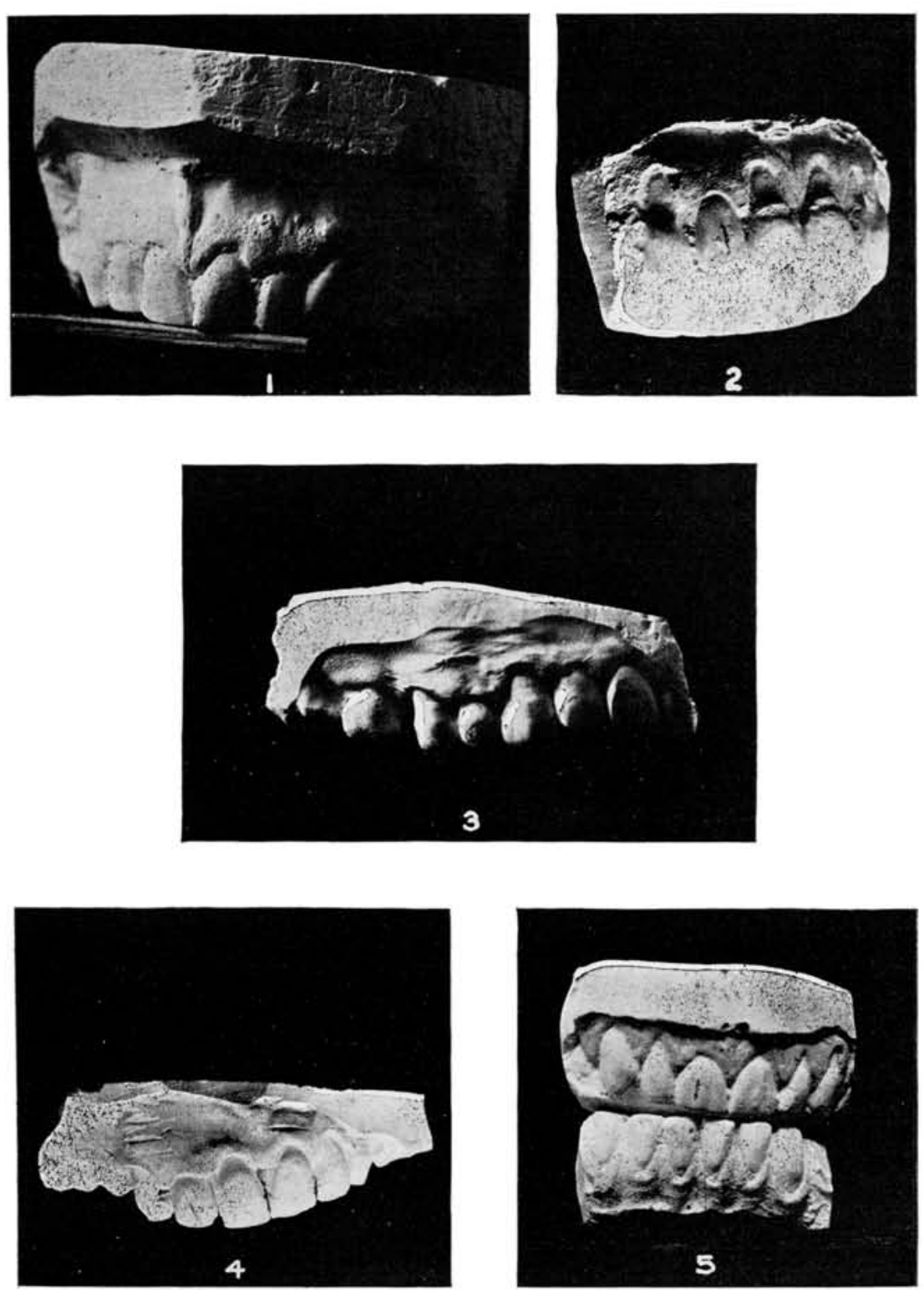

Figs. 1-5. Photographs of Models Showing Crowned Teeth on Which Recession of the Gums Did Not Occur Though It Developed on Adjacent TeEth

THE JOURNAL OF DENTAL RESEARCH, VOL. I, NO. 4 

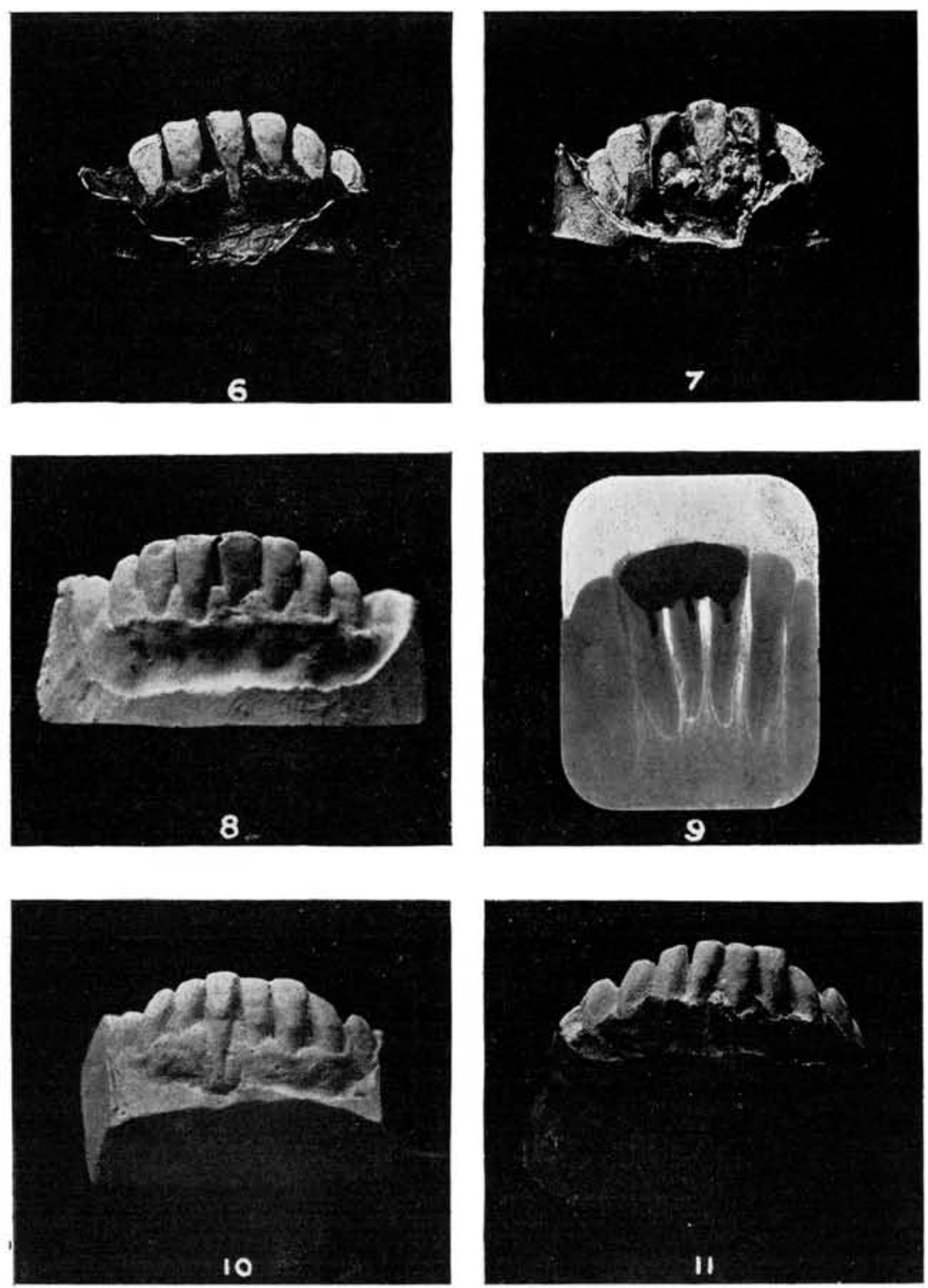

Figs. 6-11. Photographs of Models (and an Accessory Radiograph) Showing What May Be Done to Bring Back the Gums in Extreme Cases of Recession 
tooth to the gingival line, and this without performing any surgical operation, simply by keeping in mind the theory that if the gum could have a free flow of blood, it would grow and be healthy.

In slide no. 6 (fig. 6 ) is shown a model of the tooth before I started to treat it.

Slide no. 7 (fig. 7) shows the tooth under treatment. You see the gum is growing into place and the apparatus is on the teeth with the exception of the suction cup, which had to be removed to show the root of the tooth.

Slide no. 8 (fig. 8 ) shows the tooth as it is today, six years after the operation. In this slide you will see a peculiar occurrence. The right central, which was not the tooth originally affected (the one originally affected was the left central) has begun to have recession, due to the fact that this young lady had become careless and allowed great quantities of calculus to accumulate on those teeth and had not come into the office for two years, nor did she take the care she should have done. If you did not see the models or the mouth, you would be apt to say this is hypertrophied tissue, but in the mouth there is absolutely no appearance of hypertrophy; and when you understand how the growth has been accomplished, I doubt if you will say it is hypertrophy.

Notice that in model no. 6 ( fg. 6 ) the root is prominent. I put an apparatus on to press the tooth back bodily, lingually. Just as soon as that tooth was pressed back far enough, the gum showed a tendency to grow over it. We then attached a cup to the apparatus, which is bringing the root back. This cup protects the gum and also entices it to grow more rapidly.

In a short time, after you have brought the tooth into line (I have forgotten the time for this particular patient), I would say three weeks, according to the age of your patient of course, the gum will have grown to such an extent that it will overlap. Now, by freshening the edges and putting the cup back in place, the gum grows together. I have had cases which I sutured; whether this particular one was sutured or not I do not recall. I was curious when this patient came to me three or four weeks ago, to know if the pulp had died in that tooth, because it was driven back quite a distance; therefore I made an $\mathrm{x}$-ray picture of it. This shows that the roots are in per- 
fect condition and that the tooth is vital and held in place by a splint which I put on six years ago ( $f$ ig. 9).

I do not want you to understand that I am advocating this procedure as a common everyday operation. I am simply using it here as a means of proving a theory and to help in our work in another direction by showing what can be done.

Slide no. 10 (fig. 10) shows a case that is similar to the last (figs. 69). I show it because of an unusual occurrence regarding the pulp. You will notice the right lower central tooth is so badly exposed that the apex is showing. This looks as though it might be difficult to handle because of the crowding of the teeth. However, the root was comparatively easily compressed and the gum covered it as shown in model and slide no. 11 ( $f$ g. 11). You will notice a small V-shaped opening at the gingival margin where the gum has not yet united. This V-shaped space was never entirely obliterated; it did not look unsightly however.

The young lady went away and I did not see her for a year. The disfigurement at that time was so slight I did not think it worth while to do any further operating. Because the apex was exposed, as you have seen (fig. 11), I took it for granted the pulp was dead. You could actually place an instrument over the apex of the root. I sent the patient back to the dentist who had referred her to me, to have him fill the root. To my amazement he informed me the pulp was vital.

METHODS FOR THE TREATMENT OF RECESSION

\section{The author's procedure}

As far as treatment is concerned, my practice has been-and I have seen good results follow year after year-to cut down as far as practicable, the tissue of the tooth covered by that part of the gum which makes what we call the gingival space, if the gingiva has disappeared. You know we are told by histologists that the gingiva and the gum tissue are two distinct and separate tissues. Not only should you reduce as far as possible the periphery of the root-and by as far as possible I mean to the extent that you do not expose the dentinal tubules--but you should endeavor to cut into the bottom of the gingival crevice. This latter procedure will not be necessary if the 


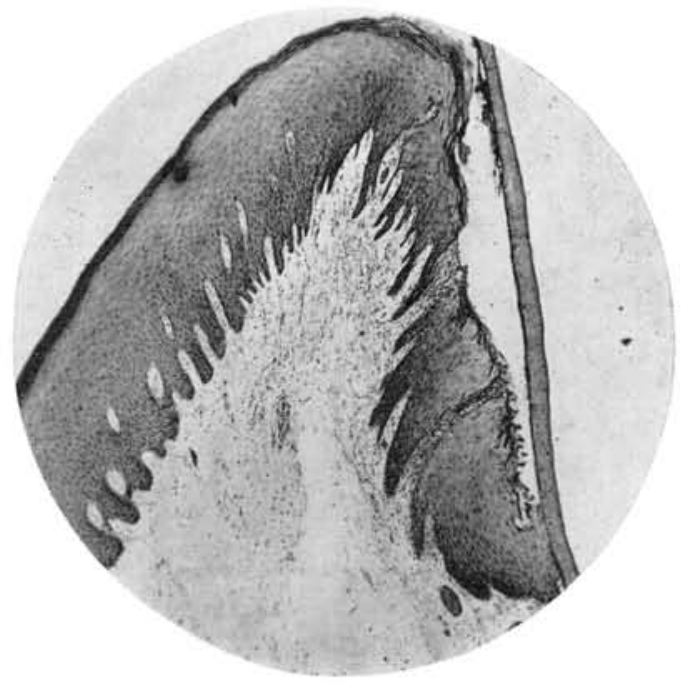

Fig. 12

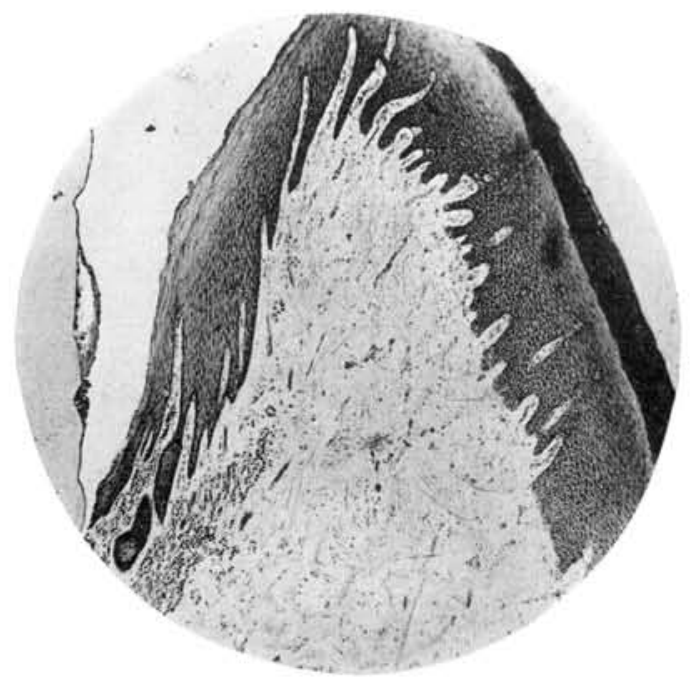

Fig. 13

Figs. 12-13. Photographs of Sections Which Show the Extraordinary Thinness of, and the Slight Amount of Protection Afforded By, the Epithelial. Tissue that Lines the Gingiva in Some Cases 
original gingival crevice has not been lost, because ordinarily prophylaxis is all that is needed. One condition that may contribute to the success of this operation is the fact that the cementum and outer layer of dentin, near and at the gingival border, are very homogeneous in character. This mass has no lacunae or, as it is sometimes expressed, bone cells. There are no blood vessels penetrating it and no canals of any size. This is not true of the cementum, however, in that portion of it which is near the apex of the tooth. Theoretically, therefore, an ideal condition obtains at the gingival portion of the tooth for reducing the periphery of the root.

Clinical experience on the other hand seems to show that, even if you cut down to the porous dentin which underlies the cementum, your operation bids fair to be successful so far as preventing recession of the gum line is concerned. But the exposure of the dentin is apt to result in sensitiveness, at least temporarily, and if the gum does not cover the exposed dentin, you invite decay at some future timenot a serious objection, if the patient returns regularly for prophylaxis, but something not to be ignored or neglected in the work.

It may seem possible to make a more secure covering for the gingival crevice than is often supplied by Nature in the epithelium that lines the gingiva. Slides nos. 12 and 13 (figs. 12 and 13) show the extraordinary thinness of, and the slight amount of protection afforded by the epithelial tissue that lines the gingiva in some cases. This is all I will say regarding this part of my subject.

\section{The Adams silver nitrate and iodin method}

There is one method of treatment with which I have had absolutely no success in this line of operations, but which is being tested by a number of enthusiasts, namely, Adams' nitrate of silver and iodin treatment.

Years ago a method was advanced for treating dental periclasia and for use in prophylaxis. That method consisted in the use of 20 per cent nitrate of silver solution on all of the gingival area before starting to operate. Adams has gone one step further and has greatly improved the treatment. Instead of applying nitrate of silver first, however, Adams advocates the application of Churchill's iodin, and 
while this latter is still on and wet, he uses from 20 per cent to 40 per cent nitrate of silver solution and gets good results in certain cases.

As a matter of fact when some good results are obtained, one is apt to claim all sorts of cures for a new method. This has been true of Adams' silver nitrate and iodin treatment. I believe there are at least two particular conditions, however, where this treatment is almost indispensable. One condition, which has come under my notice and which is always greatly benefitted by this application, is that of gingivae which are red and slightly swollen and do not yield to any of the ordinary treatments we have been in the habit of making. Adams' nitrate and iodin treatment in practically every case, will relieve this condition and, by proper instrumentation, help to obtain for you the cure that you will find very difficult to get in the same time with any other remedy.

The other condition with which I have had very little to do, is that in which white spots appear at the gingival area, in the tooth substance, and the tooth appears to be softening. The persistent application of this method to that area, it is claimed, gives extraordinary results.

Knowing Dr. Adams as well as I do, were I in general practice, I would try his method on every such case that presented itself to me.

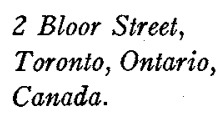

